have been copied, it may be well to say, are from the pencil of the same artist.

It should be noted that the integuments now move freely on the underlying structures.

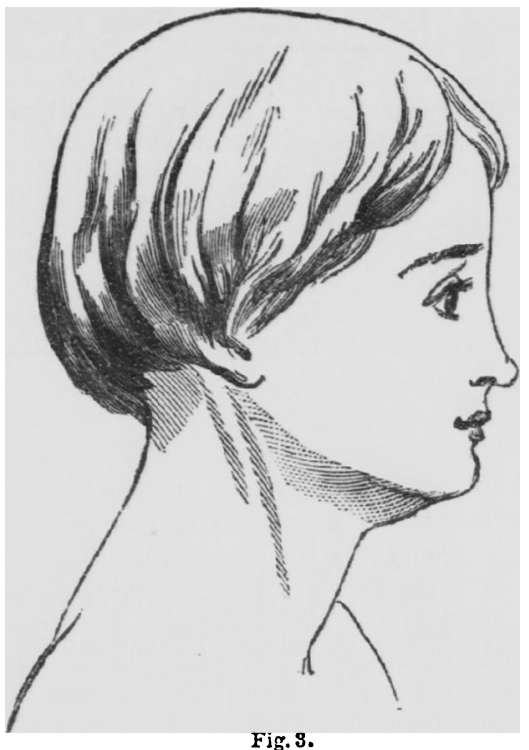

How long the extension is to be kept up after the wound has been closed is a question difficult to decide on. It is certain that the contraction goes on for a considerable time afterwards. In the case before us, the apparatus was first applied in December 1854, and it is only now laid aside.

\section{CASE OF TRAUMATIC POPLITEAL ANEURISM. TREATED SUCCESSFULLY BY COMPRESSION OF THE FEMORAL ARTERY.}

By A. D. Dunstan, Esq., Holmes Chapel.

[Read before the Lancashire and Cheshire Branch, June 25th, 1856.]

Writiay Massey, aged 38 years, a healthy agricultural labourer, fell some feet off a ladder on to the forks of a hay pike, on the 20th September, 1855. The forks caught the lower part of the left thigh, one entering the inner side of the popliteal space, the other the front part of the limb about a hand's breadth above the patella. The wounds were not larger than the iron which had produced them. They both bled very freely; but the hrmorrhage was stopped by a groom, who dexterously applied a compress of tow, secured with tape and linen.

The next day I saw him, and found the parts much swollen. He remained quiet in bed, using fomentations and other means to promote the absorption of what appeared to be a subcutaneous effusion of blood. I only saw him once, as a day or two after the injury I went from home; and on my return was told that he was walking about, nearly well-there being only a little swelling and slight stiffness of the knee.

About seven or eight weeks after the injury, I met the man, walking lamely, and found that he had not been able to resume work, as the knee was still rather stiff and swollen, and the leg swelled every day after standing.

On examining the limb, I found an enlargement of the inner half of the lower third of the thigh, with an imperfectly defined outline, soft, forcibly pulsating; a particularly loud sawing bruit was audible over every part of the swelling. Pressure on the femoral artery stopped the bruit ; and the tumour at the same time became smaller.

Having this clear indication of aneurism (which perhaps may not be quite correctly called diffused, nor yet circumscribed), I directed him to lie in bed, with the limb raised, to have the swelling gently supported by plaster, to take a mixture of antimony and digitalis, and to have lor diet. This was done, but without any result; and in the second week of December, I decided to try to effect a cure by compression of the femoral artery, by Dr. Carte's besutifully ingenious apparatus. My friends, Mr. Bland, of Macclesfield, and Mr. Carew, of Pendleton, concurred, after carefully examining the case.

I was not able to procure the instruments until the 29th December, on which day (thirteen weeks from the time of injury) the state of the limb was as follows. The tumour was very tense in the popliteal space; thence it spread up the inner side of the lower third of the thigh and half way across its front aspect. It pulsated very forcibly and visibly; it was firm around the circumference, but very soft and yielding at the most prominent part, which was at the inner side of the limb, and here the walls of the cyst appeared to be very thin, and the skin was slightly discoloured. The bruit was very loud all over the swelling. The circumference of this thigh an inch above the patella was an inch and three-quarters greater than its fellow. Below the knee the whole limb was adematous, the cutaneous veins were unusually distended, and the temperature was a little increased.

Before applying the compressors, I removed all the hair from the inguinal region and thigh, and then with ink on the skin marked out the course of the femoral artery. Over the foot and leg a well fitting stocking was drawn, as a better support than any roller bandage; but the tumour itself was left untouched. I then adjusted the one instrument to the pelvis, and the other to the middle of the thigh, and laid the limb comfortably on its outer side.

I had previously made the man and his wife (both blessed with a good portion of common sense) understand that to them must be in a great measure trusted the successful use of the instruments; as, my patient being five miles from my own residence, it was impossible for me to be with him often. I showed them how to apply the pressure, first by the one screw, then by the other, to such a degree as almost to stop the pulsation of the tumour. They promised to keep all adjusted during my absence : a promise which they faithfully fulfilled. I directed starch and oxide of zinc to be sprinkled on the skin when relieving it from pressure, and gave the man an opiate mixture to take ad libitum, so as to diminish the irritation as much as possible.

The first day or two we were all unduly anxious to effect a cure quickly, and applied the pressure more heavily and more constantly than was desirable, until the patient had been accustomed to the irritation. This made him rather restless, but, by moderating the force and altering the bearing of the compressors, undue pain was avoided; sleep was obtained by removing the pressure for a time; and then, during sleep, the screw was gently tightened without arousing the man.

This treatment went on for ten days, without any material alteration in the limb or tumour. The cedema had increased, but not to a serious extent; the temperature of the limb was not much affected, the man only complained of its feeling numbed and heavy; the skin under the pads was sore, and somewhat inflamed; but as the range of the instruments is so great, pressure could be varied in situation, and be borne without injury.

From the tenth to the fourteenth day, the cedema increased considerably, and the limb became hotter, the skin of the leg shining and rather tender. The aneurism was apparently but little altered, perhaps only a little firmer, and the firmness extended further towards the centre; the pulsation was as great as ever when the pressure was removed.

On the sixteenth day, the tumour was certainly more solid in every direction, but yet pulsating very freely, and still soft in the centre. The parts which had been pressed on being very sore, and the oedema increasing, and being satisfied that consolidation had begun, I felt anxious to remore the pressure for a few hours, so as to give my 
patient relief ; but, fearing an interruption to the cure, and the man rolunteering to continue the pressure, I determined to persevere until the morrow.

The following morning, I was agreeably surprised at being told that three hours after seeing him on the previous day, when loosening the compressor for readjustment, he found that the tumour did not pulsate, and that it had not done 80 since. Examination proved this to be correct; the tumour felt solid, free from impulse, and there was no bruit audible. The pressure was lightly applied during the next twenty-four hours, and then (January 15th) entirely withdrawn.

In the sixteen days during which the pressure was used, he took preparations of opium equivalent to one drachm of the crude drug; that is, rather less than four grains per diem. During the next fortnight, he remained quietly in bed; the oedema diminished rery slowly. He was then allowed to get up, and gradually began to move, and stand on the limb. The swelling in the popliteal space and general thickening at first prevented much bending of the knee; friction was used, and the improvement went on without interruption; and in the early part of April, he resumed his work as a labourer.

I saw him a few days ago at work; the affected thigh is still an inch larger than the other; the cutaneous veins are fuller than usual; and there is a puffiness at the ankle at night. I could not discover any of the arteries by which the leg is receiving its supply of blood. The knee can be bent to almost the natural extent; and the man is able to do a fair day's work, with only a little uneasiness about the foot and knee at night.

REMARKS. In considering the treatment to be adopted for this case, three plans presented themselves; 1st, laying open the tumour, removing the congula, dissecting out the artery, and ligaturing it above and below the wound in it: 2nd, ligature in the usual Hunterian method; and 3rd, pressure in the mode recently so often used for idiopathic aneurism.

The difficulties attending each plan would of course he greatly increased, in consequence of the man being five miles from any surgeon, in a small cottage, without any trained nurse. Of the first plan, Professor Erichsen says, it is "an operation easy in description, but most difficult and tedious in practice"; and it appeared to me in this instance to be so fraught with difficulty and danger, that I should have resorted to it unwillingly.

The following passage from Erichsen's Surgery, p. 514, appeared thoroughly to describe my patient's case, and to indicate the treatment:- "In some instances of popliteal aneurism," he says, "the aneurism has not from the first been very distinctly circumscribed. It has followed the infliction of some mechanical injury, and in the course of a week or two has acquired a considerable size, without definite or distinct limitation, being solid or but little compressible. Such a case as this can scarcely be considered a diffused aneurism; but yet if by circumscribed we mean that the blood is contained in a defined cyst with walls, it scarcely complies with such a definition, the fluid blood being rather prevented escaping widely by a temporary barrier of coagula entangled in the loose cellular tissues of the part, and the ressel being ruptured to a considerable extent or completely torn across. Here we are certainly justified in having recourse to ligature with good prospect of success."

But my conviction was, that carefully conducted pressure would insure a filling up of the aneurism as effectually as a ligature on the femoral would; and the danger to my patient under the existing circumstances would be very much less. I therefore adopted this mode; and the result shows that the decision was a sound one, and also furnishes another illustration of the great advantage accruing to patient and surgeon from this modern addition to our surgical appliances.

Whilst this case was being treated, I was not aware that this traumatic variety of aneurism had been at any time treated by compression in the manner I have described; but from a note with which Dr. Bellingham, of Dublin, has recently favoured me, I learn that there have been some analogous cases so treated with success; though this is, I believe, the first one involving the popliteal artery.

\section{ON THE DISEASES OF THE EAR PREVAILING} IN LANCASHIRE AND CHESHIRE.

By W. C. Wiumayson, Esq., M.R.C.S.Fing., F.R.S., Surgeon to the Manchester Institution for Diseases of the Ear; Professor of Anatomy and Physiology in Owen's College, Manchester.

[Read before the Lancashire and Chcshire Branch, June 25th, 1550.]

I FEen that some apology is due to the members of this Branch for presuming to bring before them the results of inquiries that have only been in progress during a period of twelve months. But having been invited to contribute something to the proceedings of this meeting, I naturally turned for my material to those investigations which I had been pursuing quietly, but assiduously, during the past year, as presenting more of novelty than anything else that I could bring forward.

It must be remembered that such inquiries are not foreign to the antecedent studies of any well educated surgeon ; consisting only in the application of well known principles of surgical and pathological science to an individual organ: consequently, any member of the profession whose preceding life has been devoted to careful scientific research may fairly expect to obtain trustworthy results in a shorter period than when the subject is wholly new, or the habit of original research has yet to be established. At the same time, I only presume to bring my conclusions before you as the first fruits of an inquiry, which I hope to continue, if life be spared, through many future years; during which period each year will necessarily add to the value of such conclusions consequent upon increased experience and familiarity with my subject.

There are probably no diseases to which medical men generally have paid so little attention as those affecting the organ of hearing. The several causes of this neglect are easily found. The comparative rarity of the cases limits the number coming under the eye of each practitioner. Hence that ready apprehension of their various aspects which can only result from constant familiarity with them can scarcely be attained, unless the opportunity is afforded of seeing them in larger numbers than usually falls to the lot of medical men. This obstacle to the study of these diseases is rendered additionally formidable by their unusual obscurity, owing to the complex structure and inaccessible position of the organ they attack. Numerous cases present themselves which must be obscure, even to the mosi experienced. Empiricism may profess to raise the reil which hides their pathology, and to read the unreadable; but to the scientific explorer, they are, as yet, like Sinaitic inscriptions on eastern rocks, having a history to reveal, but needing some Rosetta stone which would afford the clue to their interpretation.

A third obstacle to the study of these cases arises from the fact, that few of the instruments usually fo:nd in the surgeon's cabinet or pocket-case, are of any use to the aural surgeon. He requires a special array of illuminators, specula, otoscopes, and forceps.

Lastly, the idea that the practice of this branch of the profession involved little more than quackery, has further deterred men from its pursuit; it being supposed that nothing decidedly beneficial could be accomplished with the bulk of the cases. But why this imputation should rest against aural rather than against ophthalmic surgery, I have yet to learn. It originates in a baseless prejudice, if not resorted to in palliation of ignorance.

Three modes of treatment are usually adopted in these cases by the majority of medical practitioners. A patient 